\title{
An update on the diagnosis and treatment of early Lyme Disease: "Focusing on the bull's eye, you may miss the mark"
}

\author{
Amber Stonehouse \\ Thomas Jefferson University \\ James S. Studdiford \\ Thomas Jefferson University \\ C. Amber Henry \\ Thomas Jefferson University
}

Follow this and additional works at: https://jdc.jefferson.edu/fmfp

Part of the Family Medicine Commons, and the Translational Medical Research Commons Let us know how access to this document benefits you

\section{Recommended Citation}

Stonehouse, Amber; Studdiford, James S.; and Henry, C. Amber, "An update on the diagnosis and treatment of early Lyme Disease: "Focusing on the bull's eye, you may miss the mark"'" (2007). Department of Family \& Community Medicine Faculty Papers. Paper 8.

https://jdc.jefferson.edu/fmfp/8

This Article is brought to you for free and open access by the Jefferson Digital Commons. The Jefferson Digital Commons is a service of Thomas Jefferson University's Center for Teaching and Learning (CTL). The Commons is a showcase for Jefferson books and journals, peer-reviewed scholarly publications, unique historical collections from the University archives, and teaching tools. The Jefferson Digital Commons allows researchers and interested readers anywhere in the world to learn about and keep up to date with Jefferson scholarship. This article has been accepted for inclusion in Department of Family \& Community Medicine Faculty Papers by an authorized administrator of the Jefferson Digital Commons. For more information, please contact: JeffersonDigitalCommons@jefferson.edu. 


\title{
An Update on the Diagnosis and Treatment of Early Lyme Disease: "Focusing on the Bull's Eye, You May Miss the Mark"
}

\author{
Amber Stonehouse MD ${ }^{1}$, James S. Studdiford MD, FACP ${ }^{2}$ and C. Amber Henry \\ $\mathrm{MD}^{1}$ \\ ${ }^{1}$ Jefferson Medical College, Thomas Jefferson University, Philadelphia, Pennsylvania \\ ${ }^{2}$ Department of Family Medicine, Jefferson Medical College, Thomas Jefferson \\ University, Philadelphia, Pennsylvania
}

\begin{abstract}
To confidently diagnose and treat Lyme disease, the clinician must first understand the natural history of this disease, especially its protean early manifestations. Emergency physicians, primary care physicians, and other providers need to be vigilant in terms of the timely recognition of erythema migrans (EM), the unique marker of early localized stage 1 disease. The classic EM, originally described as a slowly expanding bull's eye lesion, is now recognized to be present in only the minority of cases (9\%); the dominant morphologic lesion of EM is now recognized to be the diffusely homogenous red plaque or patch, which occurs in over $50 \%$ of cases. This update will define the current morphologic features of early Lyme disease, the indication for serologic studies, and the most recent treatment guidelines, including therapeutic pitfalls.
\end{abstract}

\section{Introduction}

This article focuses exclusively on the most recent diagnostic criteria and evidence-based treatment of early Lyme disease (LD). The recognition of the early manifestations of LD by Emergency and Primary Care Physicians, as well as other caregivers, is essential, as this condition can progress to a multi-system disease if left untreated (1). One of the reasons for misdiagnosis of early LD is a lack of understanding of the protean morphologic features of erythema migrans (EM), the unique marker of early localized stage 1 disease (2). Delaying the diagnosis of EM because the lesion does not conform to a bull's eye and relying on serologic studies are often the main reasons why physicians "miss the mark" in timely recognition of early LD. Likewise, antibiotic selection specific for the treatment of this stage is crucial, or the disease can progress, as occurred in the presented case (3).

\section{Case Report}

A 31-year-old woman presented to the Emergency Department in late spring for evaluation of a slowly expanding, pruritic, burning circular red rash on the back of her left leg. The rash was accompanied by a flu-like syndrome and temperature to $38.3^{\circ} \mathrm{C}$ $\left(101^{\circ} \mathrm{F}\right)$. She recalled that the rash occurred 1 week after hiking in a Pennsylvania State Park. On physical examination, an 8-cm diffusely erythematous annular plaque was found in the popliteal fossa (Figure 1). An ELISA (enzyme-linked immunosorbent assay) titer for Lyme disease (LD) was negative. Because the lesion was not the "classic" bull's eye configuration, the physician diagnosed cellulitis and prescribed a 10-day course of 
cephalexin. One week later the patient returned for re-evaluation because the lesion had enlarged to $12 \mathrm{~cm}$ and her flu-like syndrome persisted. Another physician was consulted and recognized that the lesion was consistent with EM and represented early LD. A 10day course of doxycycline $100 \mathrm{mg}$ b.i.d. (twice a day) was prescribed and the patient improved without incident.

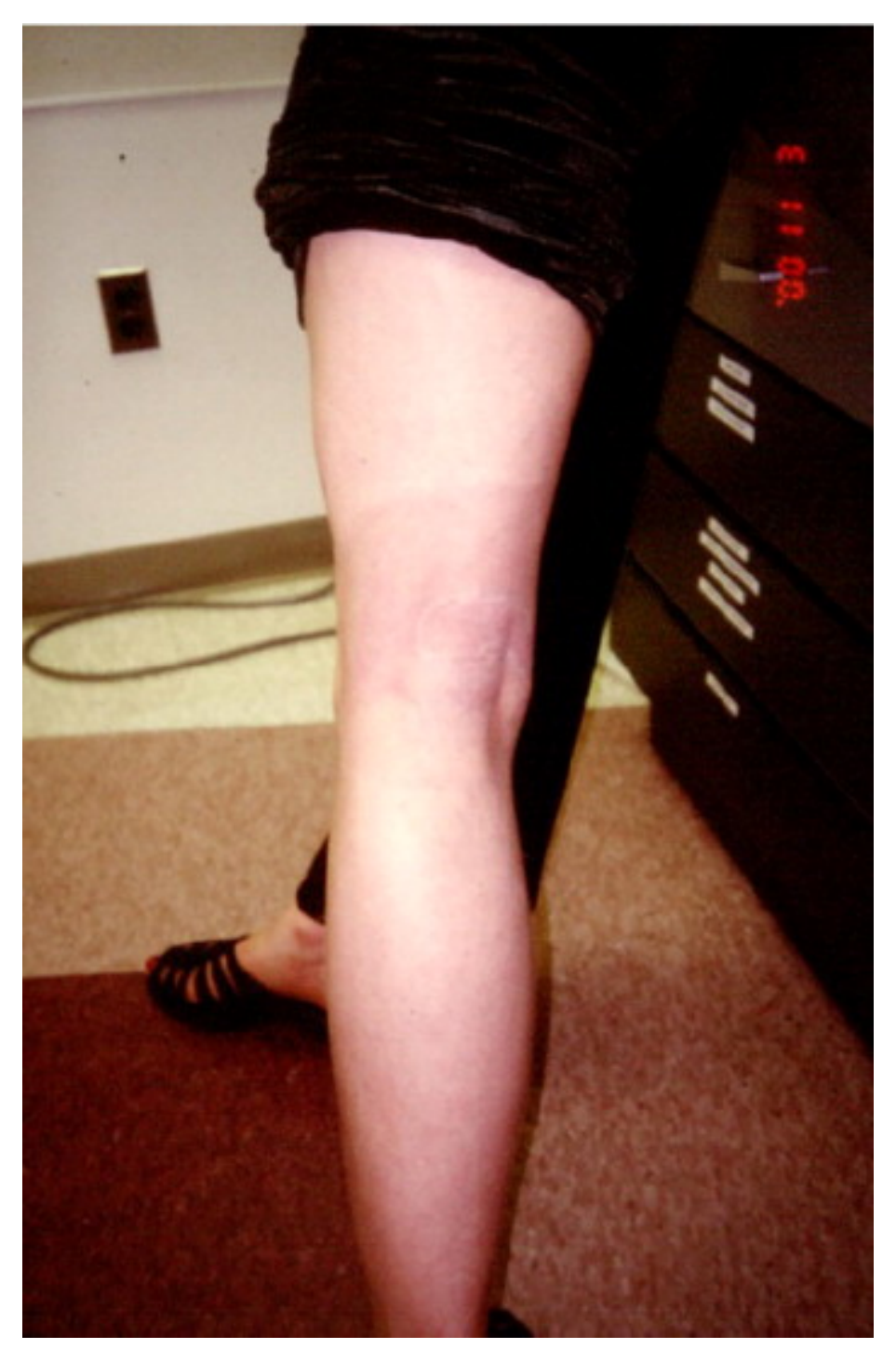

Figure 1. Case illustration, expanding EM in popliteal fossa.

\section{Discussion}

In the United States, the clinical manifestations of LD generally begin 7 to 10 days after the bite of a deer tick (Ixodes scapularis or pacificus) infected with Borrelia burgdorferi. Most infections with Borrelia burgdorferi are transmitted by the bite of a nymphal stage Ixodes scapularis tick. These ticks are round, $<2 \mathrm{~mm}$ in size, and have four pairs of legs 
(Figure 2). The epidemiologic setting is generally along the northeast corridor in the late spring or early summer. The infected tick must be attached for at least $24-48 \mathrm{~h}$ and transmits the disease in only $1-3 \%$ of bites (1). Stages of LD infection are typically defined as early localized, early disseminated, and late chronic. EM is found in most patients (60-80\%) who develop the early localized form of LD (4). This annular, erythematous lesion slowly expands to a maximal diameter of $16 \mathrm{~cm}$. The lesions may be asymptomatic, or cause burning, tenderness or pruritus, as in the above case. The rash most often occurs at or near the site of the tick bite and, if untreated, persists for 2-3 weeks. Multiple EMs may occur in 17-50\% of cases of early disseminated LD (5). The latter represents hematogenous spread of the Borrelia burgdorferi and not the occurrence of multiple tick bites.

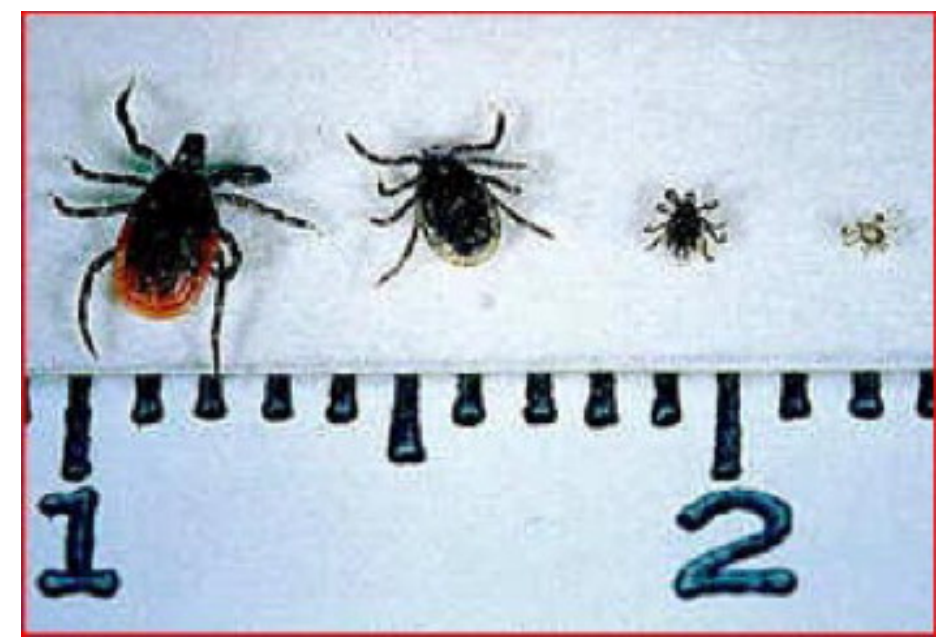

Figure 2. Different stages of tick life cycle (note infectious nymph second from right).

The EM lesion has been classically described as erythematous with central clearing, the so-named "bull's eye" appearance (Figure 3) (4). However, in a study of 118 cases of EM, in which Borrelia burgdorferi infection was confirmed by culture or polymerase chain reaction, the lesion was homogeneous in 59\%, had central erythema in 32\% (Figure 4), and was a "bull's eye" with central clearing in only 9\% (2) (Table 1). The punctum from the original tick bite is present $30 \%$ of the time (Figure 5) (2). EM also may present as a vesicular lesion, as documented in $7-8 \%$ of patients (Figure 6) $(2,6)$. A conclusion that the "bull's eye" EM lesion actually represents a small minority of cases should caution clinicians to be wary of the variety of "classic" presentations of EM. 


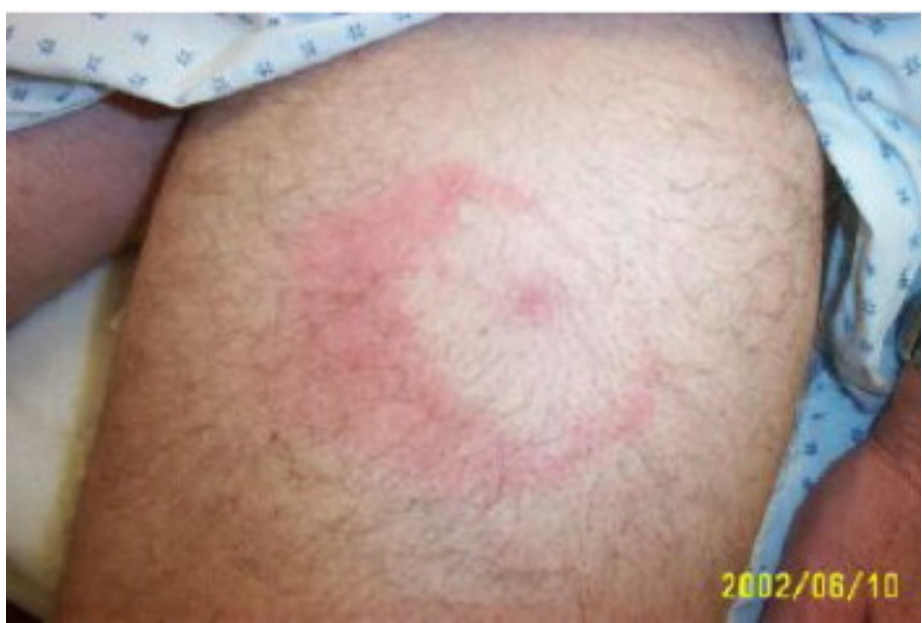

Figure 3. "Classic" bull's eye EM, expanding erythema with central clearing (9\%).

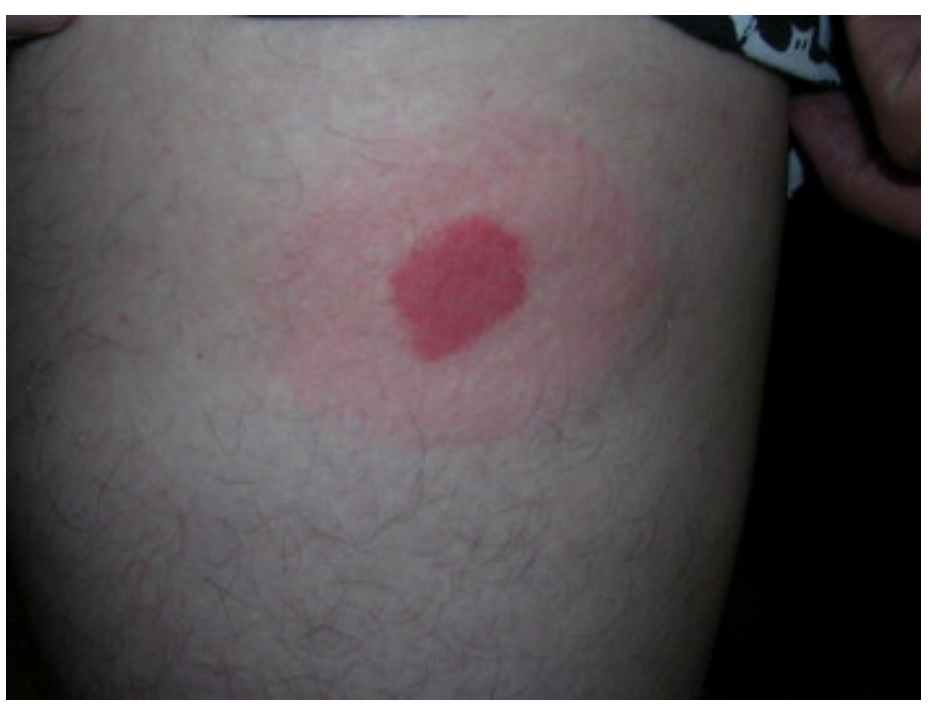

Figure 4. Diffuse homogeneous EM (50\%), central redness (34\%).

Table 1.

Morphologic Pattern of Erythema Migrans *

\begin{tabular}{|l|l|}
\hline \multicolumn{1}{|c|}{ Variable presentations } & Percentage of patients (\%) \\
\hline Homogeneous & 59 \\
\hline Central erythema & 32 \\
\hline Punctum present & 31 \\
\hline Central clearing, "bull's eye" & 9 \\
\hline Vesicular or ulcerated & 7 \\
\hline
\end{tabular}


From Smith et al. (2).

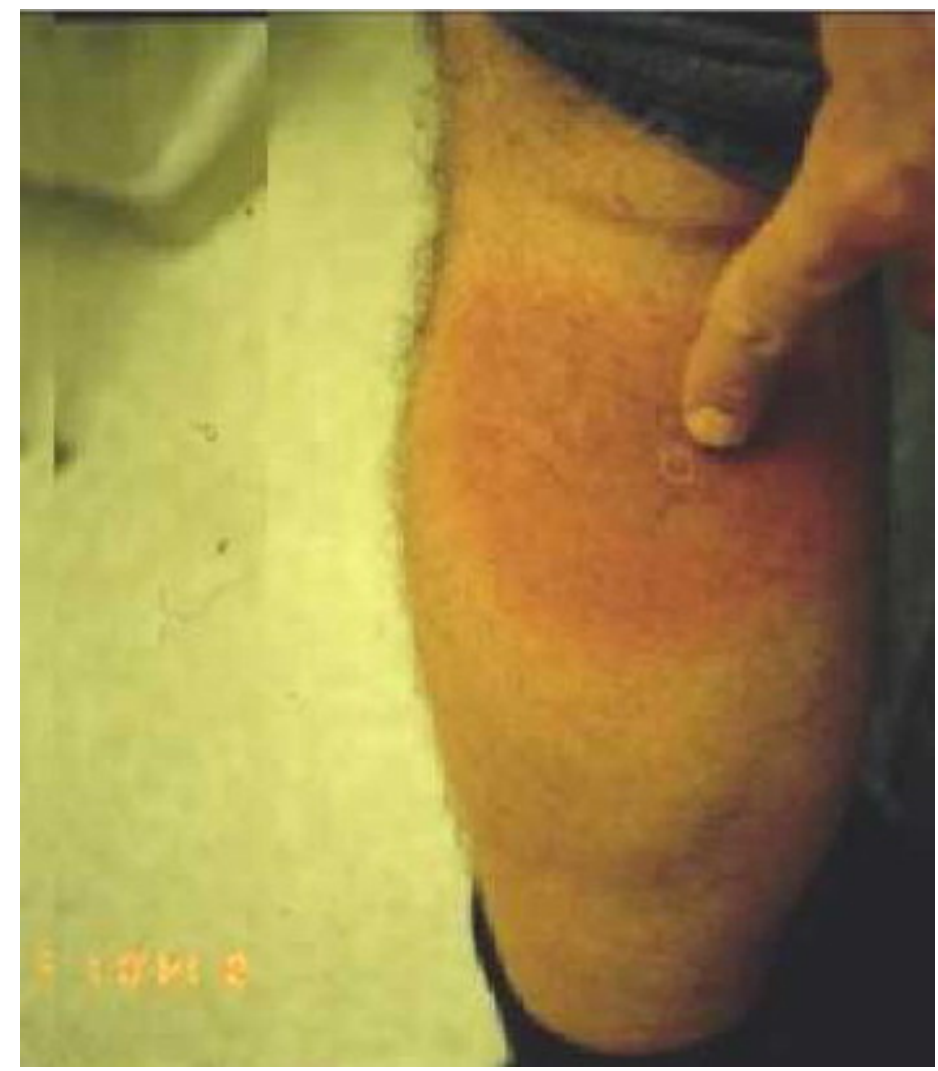

Figure 5. Homogeneous EM, with central punctum (30\%).

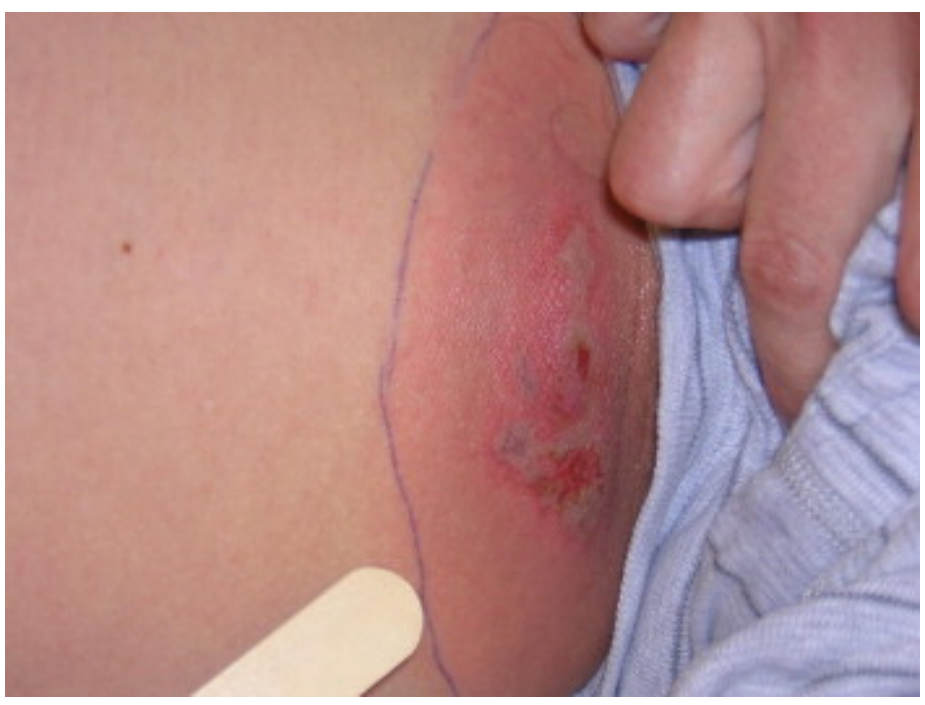

Figure 6. EM with vesicular reaction (9\%). 
Two-thirds of patients with untreated early LD are at risk of developing early disseminated LD, characterized by musculoskeletal, cardiac, or neurologic features. Cranial nerve palsies are the most common neurologic manifestation of early disseminated LD, particularly in children. More than half of children with neurologic symptoms have a facial palsy, which may be bilateral. The palsy can last from several days to 2 months. An example of a patient who presented to the Emergency Department for a Bell's palsy, subsequently determined to be secondary to LD, is seen in Figure 7. The EM can persist in patients with facial palsy and should warrant careful physical examination.

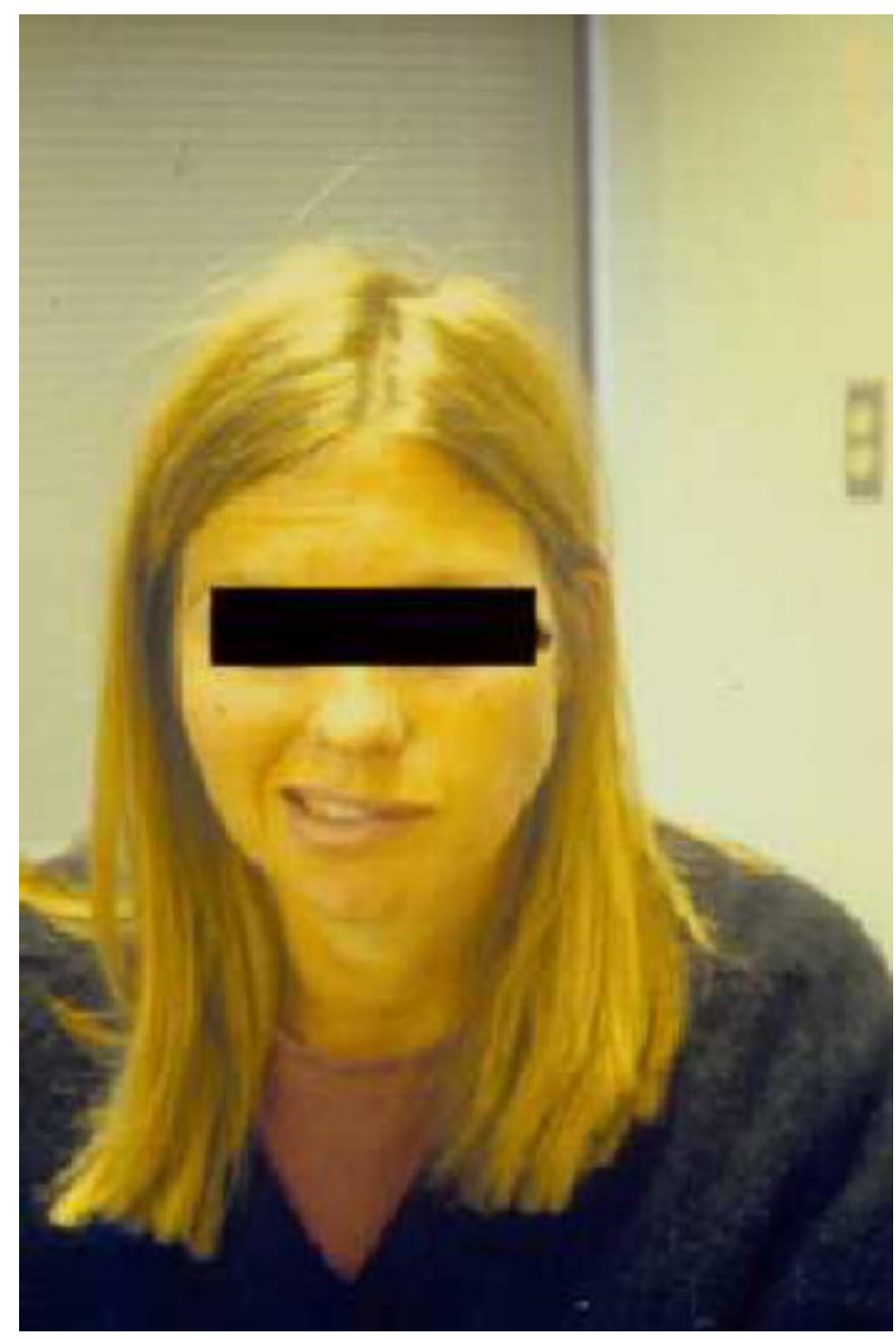

Figure 7. Bell's palsy.

\section{Laboratory Testing}


LD must be included in the differential diagnosis when encountering lesions with varying characteristics, ranging from spreading erythematous to vesicular lesions. This includes, but is certainly not limited to, insect stings, bites, drug eruptions, urticaria, contact dermatitis, cellulitis, erythema multiforme, and patients presenting with other annular lesions.

The most widely used studies for LD are antibody detection tests. These should be reserved for confirmation of tentative clinical diagnoses that fall in the low to moderate pre-test probability category $(2,7)$. If it is determined that testing is warranted, the current recommendation from the Centers for Disease Control is for a two-step testing process (8). The first step is to order an ELISA titer; this can be either a total Lyme, or separate immunoglobulin $\mathrm{G}$ and immunoglobulin M. Only in the case of a positive ELISA should the second step, confirmatory Western blot, be ordered (3). Antibody testing in patients presenting with EM, as in our case, is not indicated because the rash most often develops before the serologic conversion (3). Diagnosis in these cases should be made based on clinical acumen. Laboratory testing for early LD should be reserved for individuals from endemic areas with manifestations such as prolonged ( $>2$ weeks) unexplained flu-like symptoms without EM (4).

\section{Treatment}

Treatment for LD should be tailored to the stage of disease and the age of the patient. Patients with early acute or early disseminated LD should be treated with a 10- to 21-day course of first-line antibiotics. The 21-day course is suggested for those who are diagnosed later in the course of illness and with more severe systemic symptoms.

Doxycycline (100 $\mathrm{mg}$ b.i.d.) and amoxicillin (500 $\mathrm{mg}$ t.i.d.) have been proven efficacious for the treatment of early LD (9-15). Amoxicillin is the treatment of choice in patients under the age of 8 years. In cases of allergy or intolerance to these drugs, cefuroxime axetil (500 mg b.i.d.) is a suitable substitute and also can be given to nursing mothers (915). Macrolides provide an alternative, but less effective, therapy for patients with allergy or intolerance to the preferred regimens. Less than $10 \%$ of patients fail to respond to antibiotic therapy with doxycycline, amoxicillin, or cefuroxime axetil (9-12). The efficacy of doxycycline and amoxicillin are similar, and cefuroxime has been proven to be as effective as doxycycline in treatment of patients with early localized Lyme disease (9-12). It is important to note that the popular cephalosporin, cephalexin (Keflex), is not effective in the treatment of LD, nor are any of the fluoroquinolone class $(16,17)$ (Table 2). Treatment is highly effective for $\mathrm{LD}$ and patients who complete the recommended dose of antibiotics typically see complete resolution of symptoms.

Table 2.

Treatment of Early-Stage Lyme Disease (LD)

\begin{tabular}{|l|l|l|l|}
\hline \multicolumn{1}{|c|}{ Drug } & Adult dosage & Pediatric dosage* & \multicolumn{1}{c|}{ Notes } \\
\hline Doxycycline & $100 \mathrm{mg}$ p.o. & $>8$ years; $1-2$ & Should not be used for children < 8 years \\
\hline
\end{tabular}




\begin{tabular}{|l|l|l|l|}
\hline \multicolumn{1}{|c|}{ Drug } & Adult dosage & Pediatric dosage * & \multicolumn{1}{|c|}{ Notes } \\
\hline $\begin{array}{l}\text { (Vibramycin, and } \\
\text { others) }\end{array}$ & $\begin{array}{l}\text { b.i.d. } \times 10-21 \\
\text { days }\end{array}$ & $\begin{array}{l}\mathrm{mg} / \mathrm{kg} \text { b.i.d. } \times 14- \\
21 \text { days }\end{array}$ & old, or for pregnant or lactating women. \\
\hline $\begin{array}{l}\text { Amoxicillin (Amoxil, } \\
\text { and others) }\end{array}$ & $\begin{array}{l}500 \mathrm{mg} \text { p.o. } \\
\text { t.i.d. } \times 14-21 \\
\text { days }\end{array}$ & $\begin{array}{l}25-50 \mathrm{mg} / \mathrm{kg} / \mathrm{d} \\
\text { divided t.i.d. } \times 14- \\
21 \text { days }\end{array}$ & \\
\hline $\begin{array}{l}\text { Cefuroxime axetil } \\
\text { (Ceftin) }\end{array}$ & $\begin{array}{l}500 \mathrm{mg} \text { p.o. } \\
\text { b.i.d. } \times 14-21 \\
\text { days }\end{array}$ & $\begin{array}{l}30 \mathrm{mg} / \mathrm{kg} / \mathrm{d} \text { divided } \\
\text { b.i.d. } \times 14-21 \text { days }\end{array}$ & Okay for nursing mothers. \\
\hline Azithromycin & $\begin{array}{l}500 \mathrm{mg} \text { p.o. } \\
\text { q.d. } \times 14 \text { days }\end{array}$ & $\begin{array}{l}\text { Alternative, but less effective, fourth-line } \\
\text { therapy for patients with allergies or } \\
\text { intolerance for preferred regimens. }\end{array}$ \\
\hline Clarithromycin & 250 mg p.o. b.i.d. $\times 14$ days & \multicolumn{2}{|l|}{} \\
\hline Erythromycin & $\begin{array}{l}\text { Should be avoided. A less effective therapy, with some research indicating the } \\
\text { potential for microbial resistance. }\end{array}$ \\
\hline $\begin{array}{l}\text { Cephalexin (Keflex, } \\
\text { and others) }\end{array}$ & $\begin{array}{l}\text { Not effective in the treatment of early LD, should be prescribed with caution } \\
\text { during the summer months for patients believed to have cellulitis in locations } \\
\text { where LD is endemic. }\end{array}$ \\
\hline Fluroquinolones & Should be avoided, not effective in treatment of early LD. \\
\hline
\end{tabular}

p.o. $=$ orally; b.i.d. $=$ twice a day; t.i.d. $=$ three times a day; q.d. $=$ every day .

Data from Foy and Studdiford (3), Nowakowski et al. (16), and "Treatment of Lyme disease" (17).

* Should not exceed adult dosage.

\section{Conclusions}

In summary, although the incidence of Lyme disease is increasing, it remains an easily treatable illness when diagnosed in the early stages. Clinical recognition of the variety of "classic" skin lesions representing EM is essential in preventing the potentially devastating long-term sequelae of untreated disease.

\section{References}

1 A.C. Steere, Lyme disease, $N$ Engl J Med 345 (2001), pp. 115-123. 
2 R. Smith, R. Schoen and D. Rahn et al., Clinical characteristics and treatment outcome of early Lyme disease in patients with microbiologically confirmed erythema migrans, Ann Intern Med 136 (2002), pp. 421-428.

3 A.J. Foy and J.S. Studdiford, Lyme disease, Clin Fam Pract 7 (2005), pp. 191-208.

4 A.C. Steere and V.K. Sikand, The presenting manifestations of Lyme disease and the outcomes of treatment, $N$ Engl J Med 348 (2003), pp. 2472-2474.

5 Wolff K, Johnson RA, Suurmond D. Fitzpatrick's color atlas and synopsis of clinical dermatology, 5th edn. New York: McGraw-Hill Medical Publishing Division; 2005;67685 .

6 N.S. Goldberg, G. Forseter and R.B. Nadelman et al., Vesicular erythema migraines, Arch Dermatol 128 (1992), pp. 1495-1498.

7 D.W. Rahn, Natural history of Lyme disease. In: D.W. Rahn and J. Evans, Editors, Lyme disease, American College of Physicians, Philadelphia (1998), pp. 35-48.

8 T.B. Ledue, M.F. Collins and W.Y. Craig, New laboratory guidelines for serologic diagnosis of Lyme disease: evaluation of the two-test protocol, J Clin Microbiol 34 (1996), pp. 2343-2350.

9 R.J. Dattwyler, D.J. Volkman and S.M. Conaty et al., Amoxicillin plus probenecid versus doxycycline for treatment of erythema migrans borreliosis, Lancet 336 (1990), pp. 1404-1406.

10 E.M. Massorotti, S.W. Luger and D.W. Rahn et al., Treatment of early Lyme disease, Am J Med 92 (1992), pp. 396-403.

11 R.B. Nadelman, S.W. Luger and E. Frank et al., Comparison of cefuroxime axetil and doxycycline in the treatment of early Lyme disease, Ann Intern Med 117 (1992), pp. 273280.

12 S.W. Luger, P. Paparone and G.P. Wormser et al., Comparison of cefuroxime axetil and doxycycline in treatment of early Lyme disease associated with erythema migrans, Antimicrob Agents Chemother 39 (1995), pp. 661-667.

13 B.J. Luft, R.J. Dattwyler and M.J. Kunkel et al., Azithromycin compared with amoxicillin in the treatment of erythema migrans: a double-blind, randomized, controlled trial, Ann Intern Med 124 (1996), pp. 785-791.

14 R.J. Dattwyler, B.J. Luft and M.J. Kunkel et al., Ceftriaxone compared with doxycycline for the treatment of acute disseminated Lyme disease, $N$ Engl J Med $\mathbf{3 3 7}$ (1997), pp. 289-294. 
15 G.P. Wormser, R. Ramanathan and J. Nowakowski et al., Duration of antibiotic therapy for early Lyme disease A randomized, double-blind, placebo-controlled trial, Ann Intern Med 138 (2003), pp. 697-704.

16 J. Nowakowski, D. McKenna and R.B. Nadelman et al., Failure of treatment with cephalexin for Lyme disease, Arch Fam Med 9 (2000), pp. 563-567.

17 Treatment of Lyme disease. Med Lett Drugs Ther 2005;47:41-3. 